\title{
AN UPDATED REVIEW OF IDIOPATHIC OSTEOSCLEROSIS OF THE JAWS
}

\section{UNA REVISIÓN ACTUALIZADA DE LA OSTEOESCLEROSIS IDIOPÁTICA EN LOS MAXILARES}

Paul Marcelo Ñahuincopa López ${ }^{1 *}$ (15) marelo53@hotmail.com

\section{Luis Miguel Romero Rodríguez ${ }^{1}$} luisromero.dksa@gmail.com

\begin{abstract}
Objective: The aim of this study was to update the concepts of the diagnosis of idiopathic osteosclerosis (IO) of the jaws by digital panoramic radiographs and cone beam tomography and describe the impact of this disease on oral and general health. Methods: A search of the main databases of dental medical research was carried out using the search terms "osteosclerosis, panoramic radiography, cone beam computed tomography, jaws". Articles without language restriction until September 30, 2020 were identified. The prevalence and clinical and radiographic characteristics of $\mathrm{IO}$ of the jaws were examined in 2D and 3D imaging studies, as well as the interaction during treatments in the various dental specialties. Results: We analyzed the current situation regarding the diagnosis of $\mathrm{IO}$, with an update of the diagnostic criteria used to accurately identify IO in the latest generation imaging studies, as well determine its possible interactions in oral an general health. Conclusions: It is important to have a clear differential diagnosis of IO and be able to distinguish different radiopacities in the maxilla. Accurate reporting and monitoring of the morphometric characteristics are necessary taking into account the impact the presence of IO of the jaws has on future dental treatments.
\end{abstract}

Keywords: Osteoesclerosis, panoramic radiography, cone beam computed tomography, mandible. (DeCS)

\section{RESUMEN}

Objetivo: El propósito de esta investigación fue actualizar las consideraciones para el diagnóstico de la osteoesclerosis idiopática en radiografías panorámicas digitales y tomografías de haz cónico, a fin de determinar sus implicancias en la salud oral y general. Métodos: Se realizó las pesquisas en las principales bases de datos de investigación médica estomatológica, utilizando las palabras "osteoesclerosis", "radiografía panorámica", "tomografía computarizada de haz cónico" y "mandíbula”. Se identificaron artículos sin restricción de idioma, desde las primeras publicaciones hasta el 30 de septiembre del 2020. Se examinaron la prevalencia, las características clínicas y radiográficas en estudios imagenológicos de dos y tres dimensiones, así como su interacción durante los tratamientos realizados en las diversas especialidades estomatológicas. Resultados: La información obtenida nos permitió analizar la situación actual con respecto al diagnóstico de la OI y actualizar los criterios diagnósticos para una identificación certera de la OI en los estudios imagenológicos de última generación, así como sus posibles interacciones en la salud oral y general. Conclusiones: Es importante tener un criterio diagnóstico diferencial claro al distinguir las diferentes radiopacidades como la OI, que se pueden presentar en los maxilares, mediante un registro preciso de sus características morfométricas y seguimiento en el tiempo, teniendo en cuenta su existencia y sus implicancias en los tratamientos dentales a futuro.

Palabras claves: osteoesclerosis, radiografía panorámica, tomografía computarizada de haz cónico, mandíbula. (DeCS)
Cite as: Nahuincopa P, Romero L. An updated review of idiopatic osteosclerosis in the jaws. Rev Cient Odontol (Lima). 2021; 9(1): e050.

DOI: $10.21142 / 2523-2754-0803-2020-050$

\footnotetext{
1 School of Dentistry, Universidad Científica del Sur. Lima, Perú.
} 


\section{INTRODUCTION}

In oral and maxillofacial radiology imaging studies of multifactorial etiology, it is important for dentists to be able to recognize incidental radiological findings $\left({ }^{1-3}\right)$, with differential diagnostic criteria. Auxiliary studies with digital panoramic radiography (DPR) $(2,3)$ and cone beam computed tomography (CBCT) $(4,5)$ allow visualization of anatomical structures and asymptomatic findings of clinical relevance, such as idiopathic osteosclerosis (IO) (2,6-8).

IO is considered an incidental finding $\left({ }^{1,3}\right)$, being radiopaque, and with an estimated prevalence of $1.96 \%$ $\left.{ }^{9}\right)$ to $26.9 \%\left({ }^{10}\right)$. The characteristics of IO are a dense, calcified osteosclerotic focus with a homogeneous background, absence of medullary spaces (1), without a corticalized halo, variable in size, and single or multiple in number $\left({ }^{11}\right)$. While in most cases IO appears adjacent to the dental roots (figure 1A , 1B), it can also appear in edentulous areas without expansion of bone cortices (1) and is stationary $\left.{ }^{1}\right)$. It is more frequent in the mandible $(95 \%)\left({ }^{12}\right)$, generally around or superimposed on the inferior dental nerve (IDN) canal $\left({ }^{13}\right)$; however, it can also occur in hip and long bones $\left({ }^{14,15}\right)$.

The prevalence of IO includes the premolar $(7,16)$ and mandibular molar regions $(7,11,12,17,18)$, and is more frequent between the second and fourth decade of life $\left({ }^{7,15-17}\right)$, mainly in women $(2,4,5,7,15-17,19)$. It is also more common in African, Japanese, Chinese and Indochinese populations $\left({ }^{20}\right)$, which is important to take into account in multi-ethnic countries.

Some researchers consider IO as an anatomical bone variant which occurs during development, with no treatment and only follow-up being performed $\left({ }^{6,7,11,12,21}\right)$.

A.

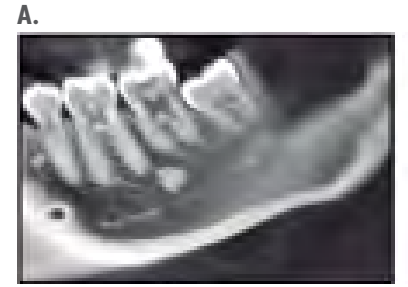

B.

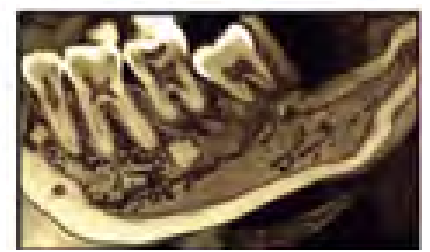

Figure I. A, 3D reconstruction showing the imaging characteristics of IO visualized as dense, calcified osteosclerotic foci with a homogeneous background. B, Panoramic image of the $1 \mathrm{O}$ adjacent to the dental roots
Non recognition of the presence of IO and the absence of criteria for the differential diagnosis of this disease makes diagnosis and treatment difficult. In addition, IO can disrupt tooth eruption leading to alterations during dental positioning in the maxillae until impaction $(1,14,19$, ${ }^{22}$ ), or complications during movement in orthodontics $\left({ }^{14,}\right.$ ${ }^{22}$ ), causing external root resorption associated with first permanent molars in $10-12 \%$ of patients ${ }^{(20)}$. Regarding the impact and interrelationship with treatments of IO in different specialties, extension and overlapping of IO in the mandibular canal can lead to the need to modify pre-surgical planning of oral rehabilitation implants $\left({ }^{7}\right)$ in order to avoid increases in temperature during drilling, denaturation of bone proteins and irreversible osseointegration $\left({ }^{8,23}\right)$. In addition, there are inconveniences in relation to anesthesia of the IDN, with a high recurrence rate being reported in the literature, despite surgical removal $\left({ }^{8,22}\right)$. Ignorance of its radiological characteristics of OI and their clinical relevance may lead us to unnecessary biopsies ${ }^{(13)}$.

In the literature, IO is also known as enostosis, osteosclerosis focus, periapical osteopetrosis or bone scar $(8,22,24-28)$. There is currently no literature guiding the differential diagnosis of $\mathrm{IO}\left({ }^{(1,3)}\right)$.

The aim of this study was to update the concepts of the diagnosis of IO of the jaws by DPR and CBCT and describe the impact of this disease on oral and general health.

\section{ARTICLE SELECTION}

A search was carried out in Medline stomatological medical research databases via PubMed, Scopus, EBSCO, Science Direct, SciELO and LILACS, using the words "idiopathic osteosclerosis, panoramic radiography, cone beam computed tomography, dentistry, oral radiology, orthodontics, oral implantology". Sixty-four articles were identified, 36 of which met the selection criteria, being analyzed without language restriction, from the first publications until September 30, 2020. The prevalence, clinical and $2 \mathrm{D}$ and $3 \mathrm{D}$ radiographic characteristics, their interaction during the treatments carried out by different stomatological specialties. Finally, descriptive 
observational study designs, and studies on prevalence and case reports were included due to the lack of other types of studies.

\section{UPDATED CRITERIA FOR THE DIAGNOSIS OF IO OF THE JAWS}

DPR is used as an auxiliary study to complement the clinical diagnosis of IO which is a common incidental finding to bone condensation $\left(^{1-3,6-8}\right)$. IO is frequently reported as a single focus $\left({ }^{2}\right)$ in the premolar and molar area in the mandible $(2,6,7,11-13,17,18,31)$ in $95 \%$ of the cases between the second and fourth $(2,7,17)$, and sometimes in the fifth decade of life $\left({ }^{7,12}\right)$. It is more prevalent in women $(2,4,5,7,19,17,19)$. and is found in the incisor, canine, premolar and molar regions in 3.7\%, 3.7\%, 44.4\%, and $48.2 \%$, respectively, of the cases $\left({ }^{7}\right)$. The most frequent localization is in the dental root in the apical area $(2,7,32)$, separated from the root $\left({ }^{14,17}\right)$ or between roots $\left({ }^{2}\right)$. The prevalence ranges between $1.96 \%$ to $11.8 \%(2,3,7,9,12,14-21$, 25, 32-34).

The mean measurements of references with respect to the area of IO are $33.9 \pm 20.1 \mathrm{~mm}^{2}$, with a height of 7.7 $\pm 3.1 \mathrm{~mm}$, width $6.6 \pm 3.1 \mathrm{~mm}$, and distance from IO to the mandibular midline of $26.6 \pm 10.7 \mathrm{~mm}$ and $9.7 \pm 3.7$ $\mathrm{mm}$ at the mandibular border $\left({ }^{7}\right)$ (figure 2).

In the DPR study IO is shown as avidity, minimal distortion, density and adequate contrast, without the presence of radiographic artifacts or evidence of tumors or trauma. The common characteristics of IO

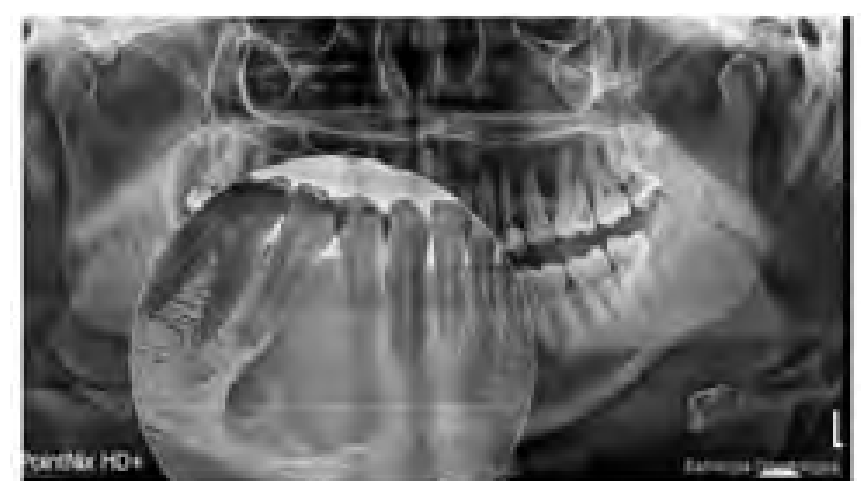

Figure 2: 10 of considerable size that includes the mean reference measurements from $33.9 \pm 20.1 \mathrm{~mm} 2$, with a height of $7.7 \pm 3.1 \mathrm{~mm}$ and a width of $6.6 \pm 3.1 \mathrm{~mm}$ shown by DPR include a radiopaque appearance with a homogeneous background, rounded shape, with regular or no borders, that do not have a radiolucent halo, no mimicking bone trabeculae no thickening of the lamina dura, single or multiple foci $\left({ }^{2}\right)$, within the vicinity of dental roots and in edentulous areas in some cases $\left(^{2}\right)$.

\section{UPDATED CRITERIA FOR THE DIAGNOSIS OF OI BY CBCT}

CBCT provides a differential confirmatory study due to the possibility of obtaining different slice proportions with volumetric reconstructions of great $3 \mathrm{D}$ avidity at a real 1:1 scale, completely eliminating the overlapping of anatomical structures, and using a lower radiation dose with respect to conventional tomography. Uniform, round or oval hyperdense images can be very clearly located in the middle of the bone trabeculae, without
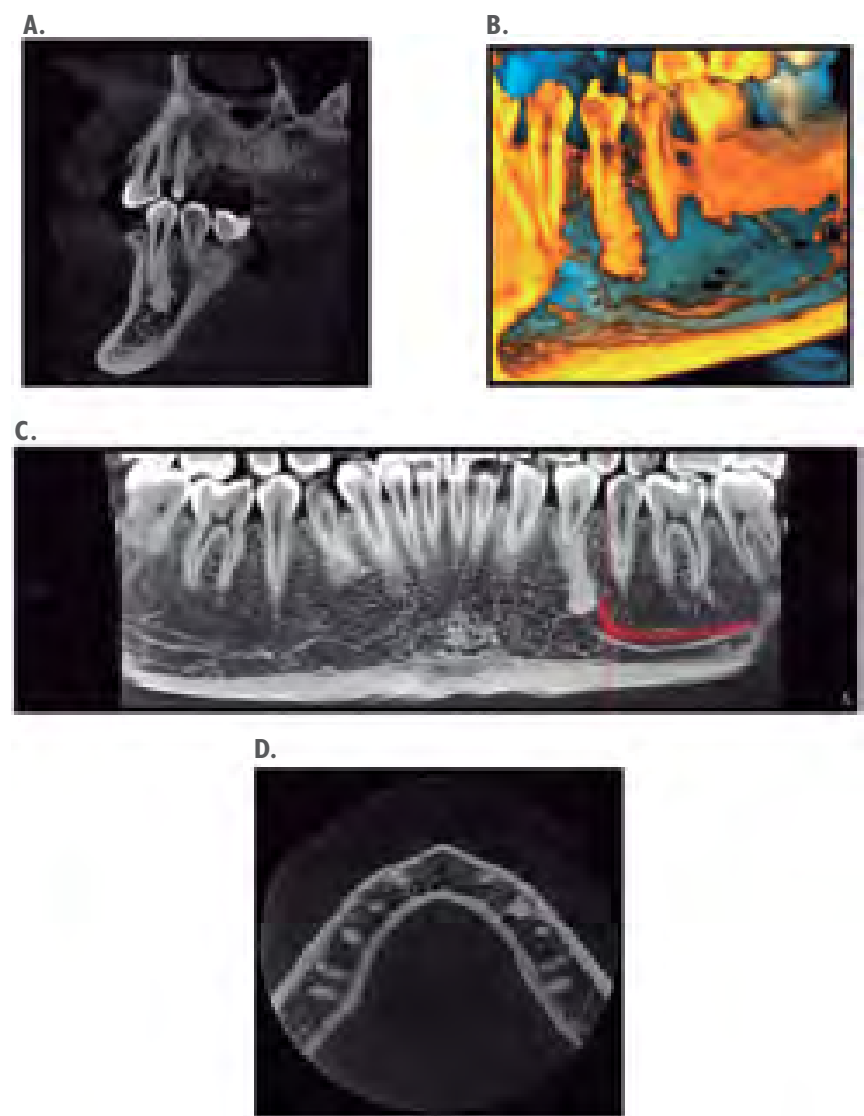

Figure 3. A: Sagittal section of the $1 O$ in cone-beam computed tomography B: $3 \mathrm{D}$ reconstruction of the $1 \mathrm{O}$. C: Panoramic slice of the 10 showing proximity to the premolar and the inferior dental nerve canal. D: Axial View of the 10 . 
surrounding hypodense areas surrounded by bone with normal radiographic characteristics. The CBCT study also determines relationships with dental roots and other important anatomical structures such as the IDN $(8,22,24,25)$ (figure 3A, 3B, 3C, 3D).

IO most frequently appears in the third decade of life $\left({ }^{26}\right)$, with a prevalence of between $16.7 \%\left({ }^{26}\right)$ and $26.9 \%$ $\left({ }^{10}\right)$ and is more common in the lower $\left(82.6 \%\left({ }^{10}\right)\right.$ to $\left.95.7 \%\left({ }^{26}\right)\right)$, than in the upper jaw $(17.4 \%)\left({ }^{10}\right)$, and in the premolar region (29.9\%) $\left({ }^{26}\right)$ molar region (52.7\%) $\left.{ }^{26}\right)$ separated from dental roots $\left({ }^{10}\right)$. The mean size ranges $1.5 \mathrm{~mm}$ to $15.6 \mathrm{~mm}\left({ }^{26,35}\right)$.

The characteristics of $\mathrm{IO}$ are that of a radiopaque round mass $\left({ }^{27}\right)$ or hyperdense area $\left({ }^{28}\right)$, with a uniform background, surrounding a bone trabecular lesion without structural alteration $\left({ }^{27}\right)$.

\section{UPDATED CRITERIA FOR THE DIFFERENTIAL DIAGNOSIS OF IO WITH DPR AND CBCT}

For the differential diagnosis of IO DPR is a preliminary examination and the characteristics of CBCT allow definitive diagnosis $\left({ }^{13}\right)$ taking into account the following clinical and radiographic criteria: the presence of circumscribed radiopaque images associated with large restorations, fixed or removable partial prosthetic abutment teeth, endodontic treatments associated with chronic processes with reactive focus such as condensing osteitis or chronic focus sclerosing osteomyelitis, mixed bone condensations with diffuse borders and different degrees of radiopacity (radiolucent-radiopaque), with the appearance of fibro-bone lesions or odontomas, cement-bone dysplasia characterized by mixed areas. Hypercementosis is shown as a hyperdense image which alters root shape preserving the lamina dura and periodontal ligament space, while cementoblastoma causes root resorption, presenting a radiopaque image with a radiolucent halo. A history of extracted teeth with the presence of root is identified by the presence of lamina dura and the space of the periodontal ligament, torus, or single or multiple bone exostoses that radiographically present as well-defined radiopacities, salivary stones, calcified lymph nodes, calcified stylohyoid ligament, calcifications of nutritional canals, foreign bodies, impacted teeth, osteocondensation with evidence of cortical expansion, patients with evident intraosseous pathology and / or craniofacial malformations in people over 40 years of age $(1-8,11,13-15,17-19,20-25,29,30,32)$.

\section{IMPLICATIONS OF THE PRESENCE OF IO IN THE JAWS}

An incidental radiographic finding of IO is considered by many researchers as an anatomical variant of normal bone during its maturation and development process. It is generally asymptomatic, does not require treatment, and only follow-up is necessary $(1-3,6,7,11,21)$.

The presence of IO is clinically associated with obstruction or deviation of the dental germ leading to alterations in the spatial position of teeth in the maxillary arches and even impaction $(1,14,20,19,22)$. In orthodontic treatment, this can cause difficulties during alignment movement, leveling and closure of spaces ( ${ }^{14}$, ${ }^{22,30}$ ), causing external root resorption associated with the first permanent molars $\left({ }^{20}\right)$. Overlapping of IO to the mandibular canal can be asymptomatic ( $\left.{ }^{35}\right)$, and is associated with persistent idiopathic orofacial pain or neuralgic pain due to compression of the trigeminal nerve, causing discomfort in the inferior dental nerve canal, and producing neuropathies $\left({ }^{24,25}\right)$. (figure $\left.4 \mathrm{~A}, 4 \mathrm{~B}\right)$ There may also be difficulties in trunk nerve block $\left({ }^{8,22}\right)$, suggesting the need for modifying pre-surgical planning during oral implant rehabilitation $\left({ }^{7}\right)$. A specific protocol

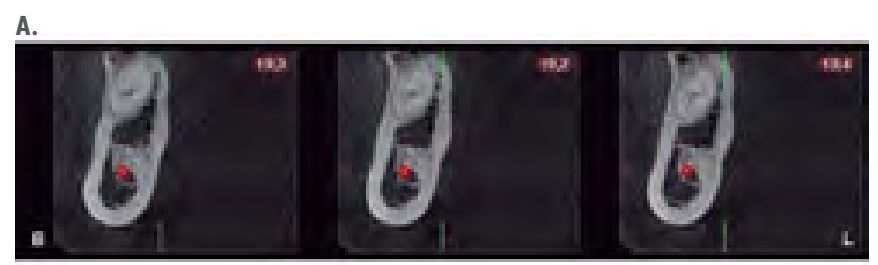

B.

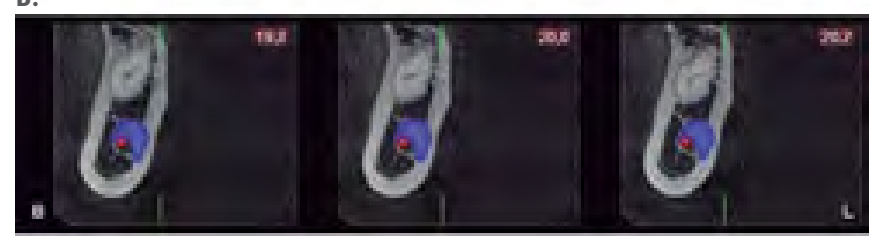

Figure 4 A, B: Sagittal view of the $1 O$ showing its proximity to the inferior dental nerve canal. 
of saline irrigation at $5{ }^{\circ} \mathrm{C}$ may be required to avoid an increase in temperature at the time of drilling denatured bone matrix proteins, negatively affecting the primary stability of the implant and osseointegration processes $(8,23)$. The incidence of recurrence is high after surgical removal of $\mathrm{IO}$, requiring the need for resection with safe margins $\left({ }^{28}\right)$. It should be taken into account that differential diagnosis would avoid the need for biopsy $\left({ }^{13}\right)$. A statistically significant correlation was also demonstrated with the presence of IO in patients with chronic liver failure due to the presence of hepatic osteodystrophy $\left({ }^{36}\right)$. These patients can present idiopathic dental pain in healthy teeth without restorations. Indeed, in patients with hepatocellular carcinoma IO led to external reabsorption of the mesial root of the lower first molar $\left({ }^{27}\right)$, intermittent paresthesia of the mandibular body, and half of the tongue, lip and lower incisor area due to invasion of IO in the dental canal $\left({ }^{2}\right)$.

\section{DISCUSSION}

This review provides updated diagnostic criteria to detect IO and interpret interactions with related entities. The etiology of IO is idiopathic, and the disease is generally asymptomatic. However, in the last decade there have been reports involving a complex diagnostic process. The prevalence of IO can be determined using DPR (3, 29, ${ }^{23}$ ), while taking into account radiographic artifacts due to overlapping images that can be difficult to interpret when IO is present in the anterior area $\left({ }^{22}\right)$. The use of CBCT has demonstrated the presence of regional block of the mandibular nerve by proximity to IO $(8,22)$, partial paresthesia of the lower lip or orofacial pain with characteristics of neuropathic pain $(8,10,22,24-28,35)$ due to compression in branches of the incisive nerve ${ }^{(28)}$ and by compression of the IDN by IO, causing neuropathies such as neuropraxia, axonotmesis, neurotmesis $(24,25,35)$.

Clinicians must become familiar with the detection and identification of bone condensation with the use of differential diagnostic criteria. IO is generally associated with healthy teeth without previous treatment and may interact with future treatments. In orthodontics and maxillary orthopedics, it is important to report cases with impactions, difficulties in closing spaces and deviations in teeth position $(1,14,19,20,22,30)$. In endodontics, idiopathic odontalgias are related to external resorption of the third apical root of the tooth in the proximity of IO $\left({ }^{20}\right)$. In cases of IO in implantology, it is necessary to apply a specific drilling protocol with irrigation of an isotonic solution at $5{ }^{\circ} \mathrm{C}\left({ }^{8,23}\right)$. In oral and maxillofacial surgery, accurate differential diagnosis can avoid the need for biopsy $\left({ }^{13}\right)$, and it should be taken into account that a high incidence of recurrence has been reported following the resection of IO $\left({ }^{28}\right)$. Apart from oral medicine, IO has also been described in long bones and hip bones $\left({ }^{14,15}\right)$. Moreover, one study described a statistically significant correlation of IO in patients with chronic liver failure $\left.{ }^{(36}\right)$. The management of $\mathrm{IO}$ requires an auxiliary DPR study. In addition, prior to the analysis, interpretation and identification of $\mathrm{IO}, \mathrm{CBCT}$ should be performed to evaluate the characteristics using $2 \mathrm{D}$ and $3 \mathrm{D}$ images providing data related to the presence of single or multiple foci, disease extension, the relationship with the dental roots, and proximity to other anatomical structures to be taken into account during follow-up.

This review highlights the importance of the incidental detection of $\mathrm{IO}$, requiring the need for follow-up of this entity due to its interaction with other diagnostic entities.

\section{CONCLUSIONS}

Timely detection of IO is important due to the possible serious impact this disease may have on oral health. It should be taken into account that many odontalgias of idiopathic nature can lead to erroneous therapeutic procedures such as unnecessary root canal treatments and extractions of healthy teeth, with persistence of the initial idiopathic pain irreversibly affecting the quality of life of the patient.

The identification of IO can be achieved by DPR which provides a detailed description of the localization of $\mathrm{IO}$ radiographic follow-up over time. However, in cases in which the clinical diagnosis is difficult and idiopathic pain of unknown origin persists CBCT should be performed. 
Authors'contributions: PaulMarcelo Ñahuincopa López and Luis Miguel Romero Rodríguez conceptualized and designed the study. They also collected and analyzed the data and made the critical review of the manuscript and approved the final version.

\section{REFERENCES}

1. Mainville GN, Lalumière C, Turgeon D, Kauzman A. Asymptomatic, nonexpansile radiopacity of the jaw associated with external root resorption: a diagnostic dilemma. Gen Dent. 2016 Jan-Feb;64(1):32-5. PMID: 26742164.

2. Pflucker S, Fiori G. Frecuencia de aparición de la osteoesclerosis idiopática y la osteítis condensante en maxilares inferiores en radiografías panorámicas. Rev Cient Odontol (Lima). Ene-Abr. 2020; 8(1): e003.

3. MacDonald $\mathrm{D}, \mathrm{Yu} \mathrm{W}$. Incidental findings in a consecutive series of digital panoramic radiographs. Imaging Sci Dent. 2020 Mar;50(1):53-64. doi: 10.5624/isd.2020.50.1.53. Epub 2020 Mar 17. PMID: 32206621; PMCID: PMC7078412.

4. Tenorio J, Quezada M, Evangelista A. Características imaginológicas de la osteosclerosis idiopática de los maxilares evaluada con tomografía computarizada de haz cónico Rev. Estomatol. Herediana. 2015 Abr-Jun;25(2):100-111.

5. Azizi, Z, Mosafery H, Safi Y, Dabirzadeh S \& Vasegh Z. Prevalence of idiopathic osteosclerosis on cone beam computed tomography images. Journal of Dental School, Shahid Beheshti University of Medical Sciences. 2017;35(2): 67-70. https://doi. org/10.22037/jds.v35i2.24626

6. Ledesma-Montes $\mathrm{C}$, Jiménez-Farfán MD, Hernández-Guerrero JC. Idiopathic osteosclerosis in the maxillomandibular area. Radiol Med. 2019 Jan;124(1):27-33. doi: 10.1007/s11547-0180944-x. Epub 2018 Sep 22. PMID: 30244367.

7. Fuentes R, Arias A, Astete N, Farfan C, Garay I, Dias F. Prevalence and morfhometric analysis of idipathic osteoesclerosis in a Chilean population. Folia Morphol 2017; 77(2):272-8.

8. Leite GM, Lana JP, de Carvalho Machado V, Manzi FR, Souza PE, Horta MC. Anatomic variations and lesions of the mandibular canal detected by cone beam computed tomography. Surg Radiol Anat. 2014 Oct;36(8):795-804. doi: 10.1007/ s00276-013-1247-5. Epub 2013 Dec 15. PMID: 24337387.

9. Avramidou FM, Markou E, Lambrianidis T. Cross-sectional study of the radiographic appearance of radiopaque lesions of the jawbones in a sample of Greek dental patients. Oral Surg Oral Med Oral Pathol Oral Radiol Endod. 2008; 106 (3): 38-43.
Funding: No funding - self-funded.

Conflict of interests: The authors declare no conflict of interests.
10. Demir A., Pekiner F. N. Idiopathic Osteosclerosis of the Jaws in Turkish Subpopulation: Cone-Beam Computed Tomography Findings. Clin Exp Health Sci 2019; 9: 117-123. DOI: 10.33808/ clinexphealthsci.563958

11. Sisman Y, Ertas ET, Ertas H, Sekerci AE. The frequency and distribution of idiopathic osteosclerosis of the jaw. Eur J Dent. 2011 Aug;5(4):409-14. PMID: 21912499; PMCID: PMC3170027.

12. Tolentino Ede S, Gusmão PH, Cardia GS, Tolentino Lde S, Iwaki LC, Amoroso-Silva PA. Idiopathic Osteosclerosis of the Jaw in a Brazilian Population: a Retrospective Study. Acta Stomatol Croat. 2014 Sep;48(3):183-92. doi: 10.15644/asc48/3/2. PMID: 27688365 ; PMCID: PMC4872826.

13. Gamba TO, Maciel NAP, Rados PV, da Silveira HLD, Arús NA, Flores IL. The imaging role for diagnosis of idiopathic osteosclerosis: a retrospective approach based on records of 33,550 cases. Clin Oral Investig. 2020 Jul 31. doi: 10.1007/ s00784-020-03477-0. Epub ahead of print. PMID: 32737665.

14. Moshfeghi M, Azimi F, Anvari M. Radiologic assessment and frequency of idiopathic osteosclerosis of jawbones: an interpopulation comparison. Acta Radiol.2014 Dec;55(10):123944. doi: 10.1177/0284185113515210. Epub 2013 Dec 6. PMID: 24316662 .

15. Solanki J, Jain R, Singh R, Gupta S, Arya A, Tomar D. Prevalence of Osteosclerosis Among Patients Visiting Dental Institute in Rural Area of Western India. J Clin Diagn Res. 2015 Aug;9(8): ZC38-40. doi: 10.7860/JCDR/2015/11439.6319. Epub 2015 Aug 1. PMID: 26436044; PMCID: PMC4576638.

16. Toraman M, Sadik E Peker I. Prevalence and distribution of idiopathic osteosclerosis on patients attending a dental school. J Istanb Univ Fac Dent. 2014; 48(2):29-34.

17. Miloglu O, Yalcin E, Buyukkurt MC, Acemoglu H. The frequency and characteristics of idiopathic osteosclerosis and condensing osteitis lesions in a Turkish patient population. Med Oral Patol Oral Cir Bucal. 2009 Dec 1;14(12): e640-5. doi: 10.4317/medoral. 14.e640. PMID: 19680185. 
18. Syed AZ, Yannam SD, Pavani G. Research: Prevalence of Dense Bone Island. Compend Contin Educ Dent. 2017 Oct;38(9): e13-e16. PMID: 28972383.

19. Yusof M, Dasor MM, Ariffin F, Reduwan NH, Kamil W, Mah MC. Idiopathic osteosclerosis mimicry of a tooth: case report. Aust Dent J. 2020 Apr 7. doi: 10.1111/adj.12756. Epub ahead of print. PMID: 32259287.

20. Marques Silva L, Guimaraes AL, Dilascio ML, Castro WH, Gomez RS. A rare complication of idiopathic osteosclerosis. Med Oral Patol Oral Cir Bucal. 2007 May 1;12(3): E233-4. PMID: 17468722.

21. Verzak Z, Celap B, Modrić VE, Sorić P, Karlović Z. The prevalence of idiopathic osteosclerosis and condensing osteitis in Zagreb population. Acta Clin Croat. 2012 Dec;51(4):573-7. PMID: 23540165.

22. Huang HY, Chiang CP, Kuo YS, Wu YH. Hindrance of tooth eruption and orthodontic tooth movement by focal idiopathic osteosclerosis in the mandible. J Dent Sci. 2019 Sep;14(3):332334. doi: 10.1016/j.jds.2019.02.001. Epub 2019 Mar 20. PMID: 31528265 ; PMCID: PMC6739255.

23. Chunga G. Consideraciones para la colocación de implantes dentales en pacientes con osteosclerosis idiopática. Una revisión de la literatura. Rev. Cient. Odontol. (Lima). Jul - Dic. 2019; 7 (2): 75-85.

24. Debevc D, Hitij T, Kansky A. Painful neuropathy caused by compression of the inferior alveolar nerve by focal osteosclerotic lesion of the mandible: A case report. Quintessence Int. 2017;48(9):725-732. doi: 10.3290/j.qi.a38905. PMID: 28920110.

25. Schreiner-Tiefenbacher B, Forster V, Pauli K, Sutter W, Meier M, Roland H, Bandura P, Turhani D. Evaluation of mandibular calcification on 3D volume images. Heliyon. 2019 May 20;5(5):e01698. doi: 10.1016/j.heliyon.2019.e01698. PMID: 31193452; PMCID: PMC6529742.

26. Zayet MK, Hassan AA. Assessment of idiopathic osteosclerosis in the jaws of the egyptian population using cone beam computed tomography. Egypt. Dent. J. April. 2019.;65(2): 1397-1401.

27. Ozemre MO, Geduk G. A Rare Complication of Idiopathic Osteosclerosis: A Case Report Journal of International Dental Sciences 2018; 3:180-182
28. Molina M, Romero V, Domínguez D, Aguilar J, Fuentes A. Extensive hyperdense zone in the mandible. A case report. Int J Med Surg Sci. 2018; 5(3): 115-119. doi: 10.32457/ ijmss.2018.029.

29. Schreiner-Tiefenbacher B, Forster V, Pauli K, Sutter W, Meier M, Roland H, Bandura P, Turhani D. Evaluation of mandibular calcification on 3D volume images. Heliyon. 2019 May 20;5(5): e01698. doi: 10.1016/j.heliyon.2019. e01698. PMID: 31193452; PMCID: PMC6529742.

30. Sinnott PM, Hodges S. An incidental dense bone island: A review of potential medical and orthodontic implications of dense bone islands and case report. J Orthod. 2020 Sep;47(3):251-256. doi: 10.1177/1465312520917975. Epub 2020 May 18. PMID: 32419572.

31. Naser AZ, Roshanzamir N. Prevalence of idiopathic osteosclerosis in an Iranian population. Indian J Dent Res. 2016 Sep-Oct;27(5):544-546. doi: 10.4103/0970-9290.195679. PMID: 27966515.

32. Farhadi F, Ruhani MR, Zarandi A. Frequency and pattern of idiopathic osteosclerosis and condensing osteitis lesions in panoramic radiography of Iranian patients. Dent Res J (Isfahan). 2016 Jul-Aug;13(4):322-6. doi: 10.4103/1735-3327.187880. PMID: 27605989; PMCID: PMC4993059.

33. Altun O, Dedeoglu N, et al. Condensing osteitis lesions in Eastern Anatolian Turkish population. Oral Surg Oral Med Oral Radiol. 2014; 2 (2): 17-20.

34. Srivathsa SH. Retrospective panoramic radiographic analysis for idiopathic osteosclerosis in Indians. J Indian Acad Oral Med Radiol 2016; 28 (3): 242-5.

35. Misirlioglu M, Nalcaci R, Adisen MZ, Yilmaz S. The evaluation of idiopathic osteosclerosis on panoramic radiographs with an investigation of lesion's relationship with mandibular canal by using crosssectional cone-beam computed tomography images. J Oral Maxillofac Radiol. 2013;1(2):48-54.

36. GhapanchiJ,Zahed M,Haghnegahdar A,Niakan N,Sadeghzadeh A. Osteoporosis and Jaw Abnormalities in Panoramic Radiography of Chronic Liver Failure Patients. Biomed Res Int. 2018 Aug 26; 2018:4280312. doi: 10.1155/2018/4280312. PMID: 30225253; PMCID: PMC6129325. 